Omer Kemal Kinaci

Metin Kemal Gokce

Ahmet Dursun Alkan

Abdi Kukner

http://dx.doi.org/10.21278/brod69403

ISSN 0007-215X

eISSN 1845-5859

\title{
ON SELF-PROPULSION ASSESSMENT OF MARINE VEHICLES
}

UDC 629.5.016.7:629.544:629.58

Original scientific paper

\begin{abstract}
Summary
Estimation of ship self-propulsion is important for the selection of the propulsion system and the main engine so that the ship can move forward with the required speed. Resistance characteristics of the vessel or the open-water performance of a propeller only are not usually enough to assess the working conditions of the ship. Both in numerical simulations and in experiments; there is a need to treat the propulsion system and the hull as a whole for a better estimation of the self-propulsion parameters. In this study, the self-propulsion points of one submarine (DARPA Suboff) and two surface piercing vessels (KCS and DTC) were obtained with methods based on computational fluid dynamics (CFD) approach. The self-propulsion points were also calculated by a classical engineering approach that makes use of the empirical relations that may be found in the literature. The results were evaluated with respect to the experiments and numerical results generated by other researchers in this field. It was found that the self-propulsion points of traditional ship forms can be very closely approximated with a classical engineering approach, given the basic geometric and the hydrostatic properties of the hull and the propeller.
\end{abstract}

Key words: self-propulsion point; DARPA; KCS; DTC; virtual disk; moving reference frame

\section{Nomenclature}

$\begin{array}{llll}B & \text { Ship breadth } & L_{p p} & \text { Length between perpendiculars } \\ C_{B} & \text { Ship block coefficient } & n & \text { Propeller rotation rate } \\ C_{M} & \text { Ship midsection coefficient } & R_{T} & \text { Total resistance of the bare hull } \\ C_{F} & \text { Skin friction resistance coefficient } & R e & \text { Reynolds number } \\ C_{P} & \text { Pressure resistance coefficient } & S & \text { Wetted area of the hull } \\ C_{T} & \text { Total resistance coefficient } & t & \text { Thrust deduction factor } \\ D & \text { Propeller diameter } & T & \text { Thrust generated by the propeller } \\ F r & \text { Froude number } & T_{m} & \text { Ship mean draft } \\ J & \text { Propeller advance ratio } & U_{G} & \text { Grid uncertainty } \\ K_{T} & \text { Propeller thrust coefficient } & U_{N} & \text { Total numerical uncertainty } \\ K_{Q} & \text { Propeller torque coefficient } & U_{V} & \text { Validation uncertainty }\end{array}$




$\begin{array}{ll}V_{A} & \text { Propeller axial velocity } \\ V_{S} & \text { Ship velocity } \\ w & \text { Taylor wake fraction } \\ W_{n} & \text { Nominal wake } \\ W_{T} & \text { Effective wake fraction }- \text { ITTC } \\ \eta & \text { Propulsion efficiency }\end{array}$

\section{Abbreviations}

$\begin{array}{ll}C E A & \text { Classical engineering approach } \\ C F D & \text { Computational fluid dynamics } \\ \text { DTC } & \text { Duisburg Test Case } \\ \text { KCS } & \text { KRISO Container Ship }\end{array}$

$\begin{array}{ll}\eta_{0} & \text { Open-water propeller efficiency } \\ \eta_{H} & \text { Hull efficiency } \\ \eta_{R} & \text { Propeller relative-rotative efficiency } \\ \lambda & \text { Scale of the model } \\ \rho & \text { Water density } \\ \nabla & \text { Displacement }\end{array}$

$M R F \quad$ Moving reference frame

$S F C$ Skin friction correction formula by ITTC

VOF Volume of fluid

\section{Introduction}

Predicting the self-propulsion point of a marine craft is a challenging issue because of its geometry and complex hydrodynamic interaction between the ship and the propeller. Computational Fluid Dynamics (CFD) approach gives an opportunity to simulate the flow around a ship and propeller in a more economical way compared to the experimental methods. In the last three decades, researchers became capable of simulating ship flow with higher mesh numbers and smaller time steps thanks to the rapid development of computing technology. Several works are present about hull-propeller interaction and self-propulsion calculations using CFD approach. Potential flow based CFD methods are still widely used to numerically simulate the flow around ships and propellers. On the other hand, recent research shows that Reynolds Averaged Navier-Stokes Equations (RANSE) based methods started becoming a spearhead for ship resistance and propeller flow simulations. Though not very common, coupled methods utilizing the boundary element method (BEM) and RANSE also get a foothold in recent studies. Although CFD is the most popular method for propulsion simulations lately, experiments which are the workhorse of the industry are still touted as the most trusted option. In a recent study, the effect of the propeller on the stern region was experimentally examined by Pecoraro et al. using Laser-Doppler Velocimetry (LDV) [1].

Experiments are also used for validating numerical approaches. Bugalski and Hoffmann found accordance in ship self-propulsion results generated by RANSE and experiments using sliding grids [2]. Theoretical derivations are also useful to assess the efficiency of numerical methods. Actuator disk method has proved its worth in time for ship propulsion simulations. A comparison of RANSE and actuator disk methods with respect to the experimental data was made by Gao et al. and advantages of each method were demonstrated [3]. A coupled approach joining field methods (RANSE) and panel methods (BEM) were used to reduce high computational costs of ship self-propulsion simulations. Forces acting on the ship hull should be calculated with RANSE to include viscosity while potential flow approach implementing BEM is enough to calculate the thrust generated by the propeller. This model was first proposed by Stern et al. and various applications are present in the literature such as the study of Berger et al. $[4,5]$. The model was based on a body force approach where additional terms were added to the Navier-Stokes equations to model the interaction. Gaggero et al. performed a successful ship self-propulsion prediction by utilizing a coupled approach which was developed by Villa et al. $[6,7]$. Starke and Bosschers also made use of this coupled approach and discussed the scale effects in ship resistance and propulsion [8]. 
Model scale CFD simulations are more common due to the difficulty of high Reynolds numbered full scale simulations. Castro et al. performed CFD simulations for predicting the full scale KRISO Container Ships (KCS) self-propulsion [9]. Grid structure has an intense effect on propulsion simulations especially in resolving the flow field; however, Da-Qing stated that computing the forces acting on the propeller can even be found with a coarse mesh structure [10]. Self-propulsion is also a critical issue for submarines. Chase and Carrica studied on DARPA Suboff and its propeller E1619. RANSE, DES (Detached-Eddy Simulation), DDES (Delayed Detached-Eddy Simulation) and NTM (No Turbulence Method) approaches were used and investigated for comparison [11].

Recently, overlapping grids for the propeller section were started to be used effectively in RANSE propeller simulations. Chao et al. simulated an ice flow field in front of a propeller and investigated the effects of gap between the ice and the propeller on the propeller hydrodynamic coefficients by implementing an overlapping grid structure around the propeller [12]. Another approach to numerically simulate a rotating propeller during a ship's surge motion is using the sliding mesh. Wang et al. dealt with the influences of the skew angle variance on propulsion performance and the trailing vortex wake [13]. They utilized RANSE based CFD method with sliding mesh technique for open water propeller simulations of a series of DTMB propeller models and achieved compatible results with the experiments. They concluded that increment of skew angle has benefits on hydrodynamic performance of DTMB series. Go et al. numerically examined the effects of a duct using KP505 propeller [14]. Different duct diameter and angle of attack conditions were simulated after a validation study. Detailed post-process illustrations were presented about the hydrodynamic effects of a duct on the propeller.

The present study deals with the estimation of self-propulsion points of vessels using numerical simulations and empirical relations. Numerical simulations can be made for single vessel and single propeller cases to model the interaction via propeller wake and thrust deduction factor. In that case, simulations are conducted for isolated hull and isolated propeller. Propeller wake and thrust deduction factor may be obtained computationally, numerically or via empirical relations and statistical regressions etc. Numerical simulations can also be made for self-propelled case, where the vessel and the propeller are modelled together to predict the self-propulsion of the ship. Another option is to use a basic engineering approach and making use of some empirical relations that may be found in the open literature for the estimation of the self-propulsion point. These methods were used to predict the propulsion performances of the DARPA Suboff, KRISO Container Ship (KCS) and the Duisburg Test Case (DTC). Experimental and numerical results of other researchers for these benchmark ships exist in the literature and comparisons were made with them where applicable.

\section{Numerical estimation methods of ship self-propulsion point}

Ship self-propulsion point can be estimated by experimental or numerical self-propulsion tests. The self-propulsion point of a ship can also be predicted if bare hull resistance and openwater propeller performance are known. The communication between the total bare hull resistance and open-water propeller performance can be set up via propeller wake and thrust deduction factor.

A working propeller will change the flow, especially at the stern region of the hull. The effect of the propeller on the total resistance will be accounted to the thrust deduction factor. The existence of a hull in front of the propeller will change the incoming flow on the propeller disk. This will be accounted to the propeller wake. Therefore it may be said that the hullpropeller interaction is governed by two non-dimensional parameters, namely the propeller 
wake, $w$ and the thrust deduction factor, $t$. If experimentally or numerically the self-propelled case is not tested, then the interaction should be investigated using these two parameters. In this section, the different methods used in this study to predict the self-propulsion of ships were presented.

2.1 Estimation of self-propulsion point by a classical engineering approach

Given the geometric and hydrostatic properties of a hull and a propeller; an engineer can specify the self-propulsion point of that hull-propeller system with a basic engineering approach. The engineer also requires the following to assess the propulsive characteristics of the ship:

- Total towed resistance (with no propeller), $R_{T}$ : The total ship resistance can be obtained from model experiments, computational fluid dynamics approach or using empirical relations.

- Wake fraction, $w$ : Wake fraction of a hull can be obtained from model experiments. It can also be obtained by calculating the axial velocity $V_{A}$ that the propeller receives by CFD and using equation (1). There are also some empirical equations provided in the literature such as the one suggested by IMO [15].

- Open-water thrust coefficient, $K_{T}$ : Thrust coefficient of a propeller can be obtained experimentally from open-water propeller tests. Open-water propeller tests can also be numerically simulated using field (finite volume) or panel (boundary element) methods.

- Thrust deduction factor, $t$ : The thrust deduction factor can experimentally be determined. Experiments should be conducted for the hull with and without the propeller both and they should be used in equation (4) (or equation (5) if the experiments are made for the model scale). Same procedure can also be followed numerically to obtain $t$. Numerical approach can either be carried out by modelling the propeller itself or using a virtual disk to represent it. Empirical relations such as the one proposed by IMO serve another option [15].

As briefly explained above, these values can be empirically calculated if available in the literature. Using the results of experiments or computational fluid dynamics approach are other options. With these parameters in hand, the methodology would be as follows:

a. Using wake fraction w, calculate the axial velocity $V_{A}$ that the propeller receives using the equation:

$$
w=\frac{V_{S}-V_{A}}{V_{S}}
$$

It must be noted here that the wake fraction provided in equation (1) is the Taylor wake fraction in general. The Taylor wake fraction in thrust identity defined by the ITTC is different and defined in ITTC [16]. Axial velocity $V_{A}$ can also be directly calculated if experimental or numerical methods are followed.

b. Select an arbitrary value of propeller rotation rate $n$ and calculate the advance ratio $J$, using $V_{A}$ obtained from equation (1) with the equation:

$$
J=\frac{V_{A}}{n D}
$$

c. Obtain thrust coefficient $K_{T}$ at the advance ratio $J$ (obtained from equation (2)) using the open water propeller performance curve. Intermediate values of $J$ can be calculated by interpolation or by fitting an equation. 
d. Determine the thrust $T$ using the thrust coefficient $K_{T}$ from the open-water results using the equation:

$$
K_{T}=\frac{T}{\rho n^{2} D^{4}}
$$

e. If the calculations are carried for the full scale ship, the total towed resistance $R_{T}$ should be equal to the thrust $T$ generated by the propeller times $1-t$. This relationship is more widely known with the equation:

$$
t=\frac{T-R_{T}}{T}
$$

However; if the calculations are carried out for a model ship, then a skin friction correction (SFC) must be made. This is due to the fact that the frictional resistance coefficients of the model and the full scale ship are not equal. This is explained in greater detail in ITTC [16]. Equation (4) in this case becomes:

$$
t=\frac{T-R_{T}+S F C}{T}
$$

f. If $R_{T}-S F C \neq T(1-t)$, return to point b to select another propeller rotation rate $n$. It should be noted that $S F C=0$ if the experiments are made for the full scale ship. Skin friction correction equation is given as:

$$
S F C=\left\{(1+k)\left(C_{F 0 M}-C_{F 0 S}\right)-\Delta C_{F}\right\} * \frac{1}{2} \rho S V_{S}^{2}
$$

The flow diagram of the procedure explained above is given in figure 1 .

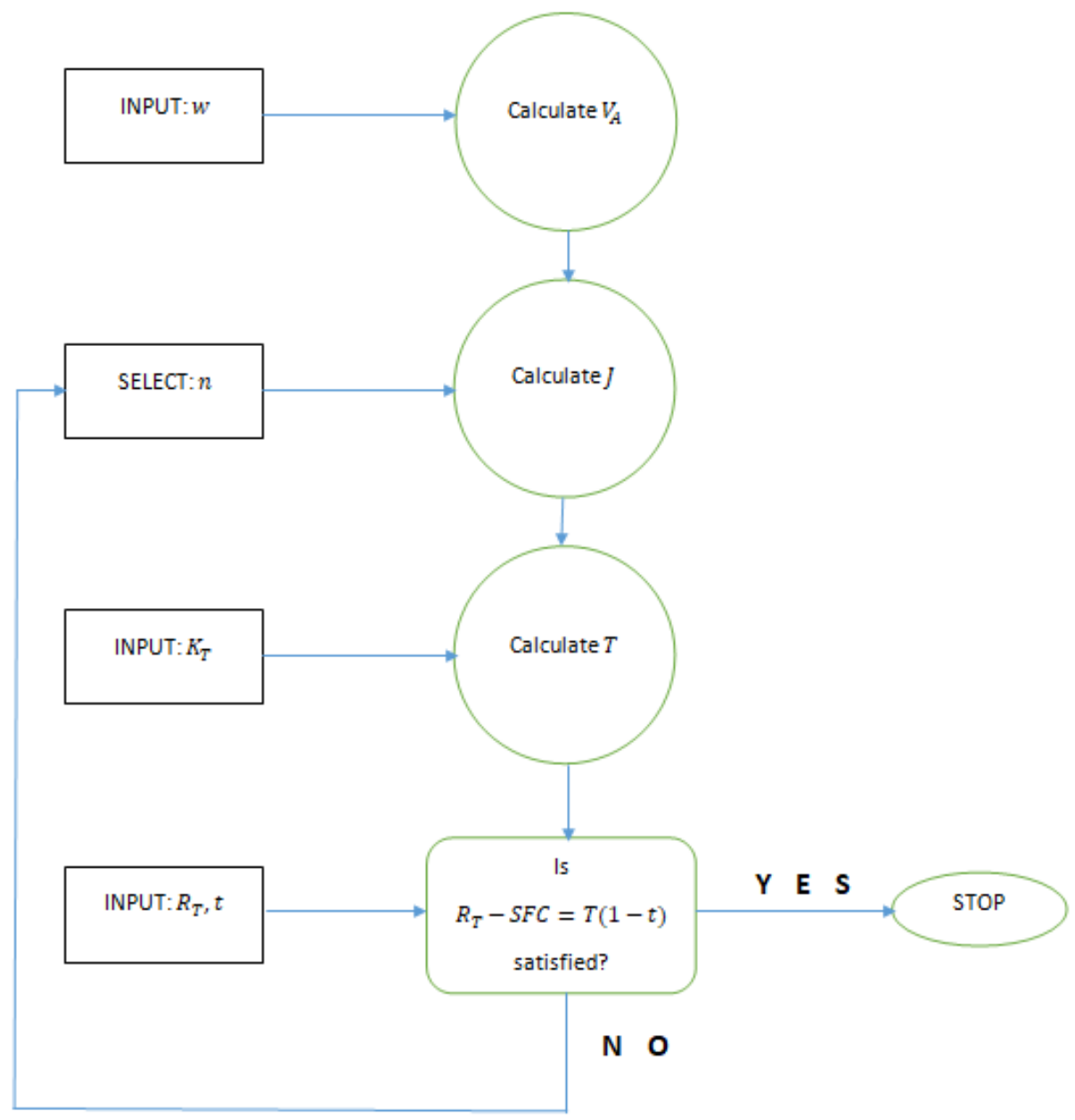

Fig. 1. Flow diagram of the classical engineering approach adopted in this study. 
The flow diagram presented in figure 1 reflects the authors' choice to obtain self-propulsion parameters at the initial design stage. There are many other methods to approach the problem such as making use of the auxiliary quantity $K_{T} / J^{2}$ as in reference [6].

\subsection{Self-propulsion approximation using "virtual disk"}

The self-propulsion point of a marine vehicle can computationally be estimated without directly modeling the propeller itself. A virtual disk that totally covers the propeller geometry is created at the position of the propeller and it uses the propeller's open-water performance characteristics. Figure 2 summarizes how a virtual disk is created in numerical simulations.

It must be mentioned that the virtual disk in figure 2 (right) does not contain the propeller geometry. It is only a cylinder that is "considered" to model the propeller. Implementation of virtual disk is handy at the preliminary design stage of a ship due to the following:

- handling the geometry is relatively easier at the CAD stage and

- reduces the number of elements needed to physically model the propeller.

However it must be noted that the open-water propeller performance of the propeller is a prerequisite to use the virtual disk. All self-propulsion simulations with virtual disk in this study are based on the body force propeller method. The method does not take propeller swirl into account and therefore it is advised to be used when there is no need to solve the flow in the vicinity of the propeller. The method is especially handy when one needs to understand hullpropeller interactions instead of resolving the flow field in the wake. A recent study utilized this method to investigate hull-propeller interactions through simulations of self-propulsion tests [17].
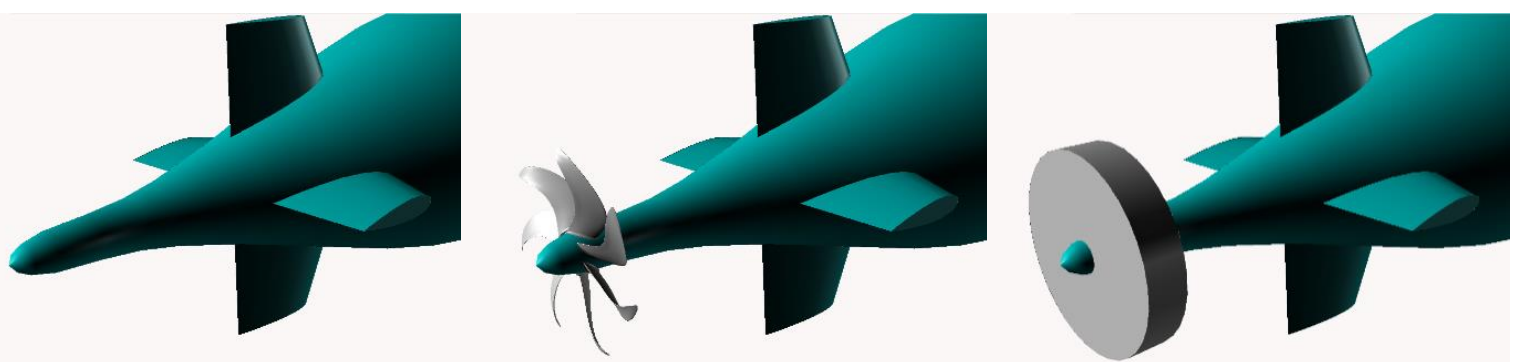

Fig. 2. Hull without a propeller (left). Hull with a propeller (middle). Hull with a virtual disk at the position of the propeller (right). The propeller is not present in the virtual disk.

\subsection{Numerical simulation of self-propulsion tests}

The hull-propeller system can be directly simulated numerically to determine the selfpropulsion point of a ship. This method is of course more realistic as the real geometry of the propeller is included in the simulations. There are various ways to directly simulate the hullpropeller system and the initial conditions of the simulation should be selected accordingly:

- Propeller starts its rotation when the ship has zero forward speed.

If this approach is selected, then the simulation must be ran in transient mode. Initially, the propeller rotation rate is given but the ship is stationary. The ship starts moving and after a while it reaches a steady forward speed with the thrust generated by the propeller.

- Propeller starts its rotation when the ship is moving with a specified forward speed. In this approach, force balance should be closely investigated. The thrust generated by the propeller should be equal to that produced by the total resistance of the hull. A timeindependent approach may be implemented using a moving reference frame to model the propeller rotation. 
In this study, the second option is selected to obtain the self-propulsion point directly using CFD. Therefore; the force balance was closely observed and the propeller rotation rate was iteratively found for a specified velocity of the ship.

\section{Numerical implementation}

A commercial software, Star CCM+ was used to numerically simulate all the cases involved in this study. Due to flows having high Reynolds numbers, a turbulent flow approach implementing the $k-\epsilon$ turbulence model was selected. $y^{+}$values were checked and were in accordance with the requirements of the selected turbulence model. The free surface boundary was tracked using the Volume of Fluid (VOF) approach where applicable. The DARPA suboff was considered to be totally submerged and far from free surface; therefore, a single phase (containing water as the only fluid in the domain) numerical approach was adopted.

To assess the propulsive characteristics of ships easily, a virtual disk surrounding (but not including) the propeller is created and open-water propeller performance was imposed on the solver. Virtual disk provides easier generation of the model and uses lower computer memory due to the lesser number of elements used. For the cases of ships including the propeller, a moving reference frame (MRF) method was used. MRF allows solving the ship-propeller interaction problem via a quasi-transient approach. The propeller remains fixed in the flow but the domain just surrounding the propeller is given a rotation instead, which accelerates the fluid particles in the selected region. A sample grid system around the DARPA Suboff with a propeller is given in figure 3. The propeller is inside the cylindrical domain at the stern part of the hull. Some more details about the moving reference frame is explained in the related section.

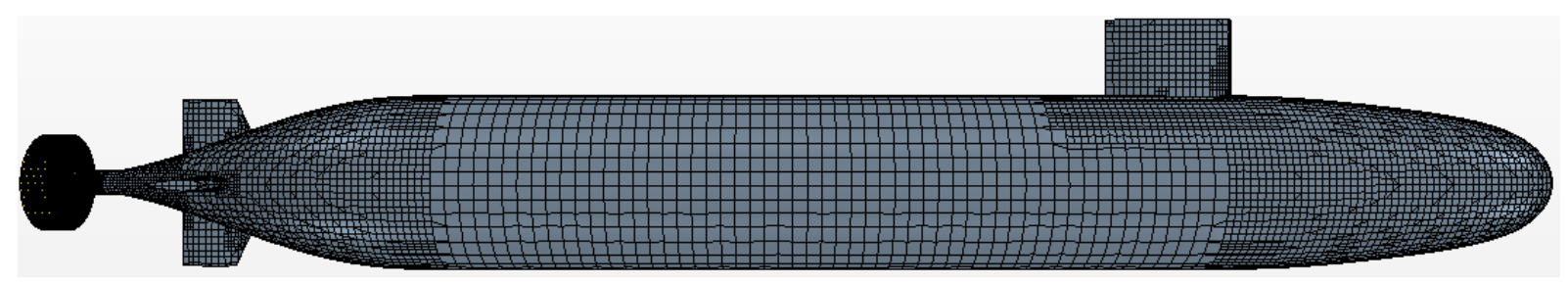

Fig. 3. Grid system on the DARPA Suboff surface.

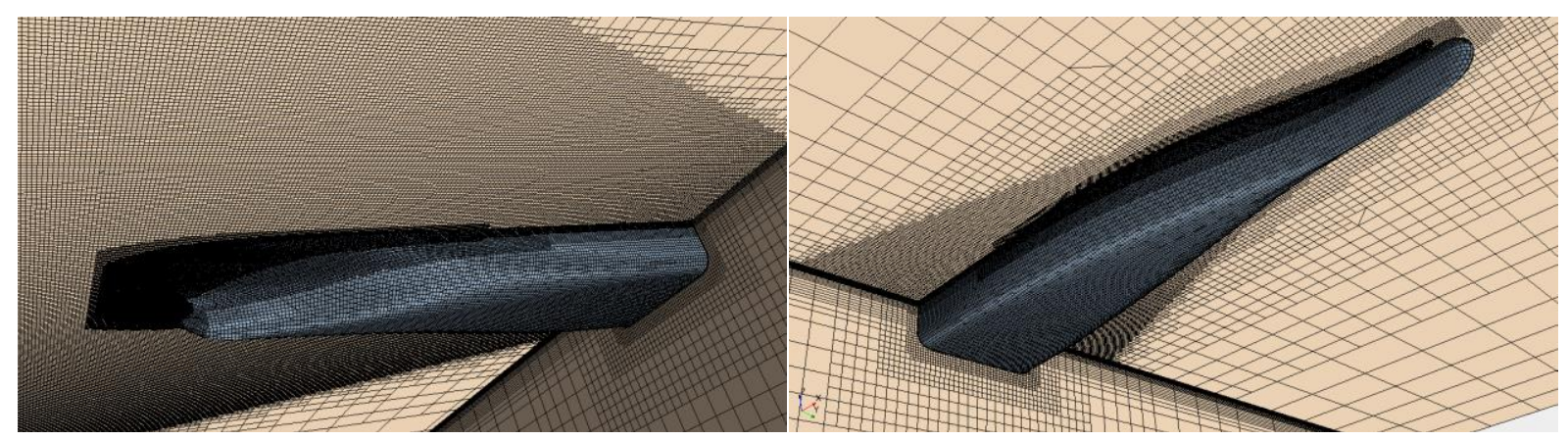

Fig. 4. Grid structure around the underwater hull of KCS. Stern (left), bow (right).

To correctly capture the waves generated by the hull for surface piercing ships, a Kelvinwave refinement is made. This refinement can clearly be seen in figure 4 (left), starting from around the midship and extending $2 L$ to the wake region. The reason of not extending the Kelvin wave refinement region up to the bow region of the ship was to save from computational time and memory. The aim of this study was to focus on the self-propulsion characteristics of ships; 
therefore, the number of elements used in simulations was tried to be optimized. Only the places where the propeller would get affected were refined. Refinements over the hulls were also made to places where pressure gradients were expected to be high like the position of the bulbous bow in figure 4 (right). For better approximation of viscous forces, at least 4 prism layers were used on the hulls.

\section{Moving reference frame}

Moving reference frame offers a time-averaged solution rather than a time accurate one. The propeller is held stationary while the surrounding block is given a rotation. This rotation of the block is not a real one, as the grid elements are always stationary throughout the simulation. However, the flow is being rotated in the opposite direction of the actual direction of propeller rotation. The flow rotation defines relative velocities and generates flux for each grid in the block surrounding the propeller. An increase in the propeller rotation rate is reflected as an increase in the flux at each grid. The communication with the outer fluid domain is made by an interface in between the two regions. For a diagrammatic explanation of the moving reference frame, figure 5 may be referred.

A good advantage of the moving reference frame is the flexibility of this method to be used in steady state approaches. In this study, all self-propelled CFD simulations were performed using moving reference frame in steady state. The relative positioning of the propeller would not be dominant in results if one is to obtain quantitative data of the propulsion system of a ship such as thrust or torque coefficients, thrust deduction factor, propeller efficiency etc. The transient behavior of ship-propeller interaction would be significant in cases such as cavitation phenomenon or noise generation. The propeller rotation rates were all low in the cases investigated in this study; therefore, cavitation is left out of the simulations. Moving reference frame provides a faster and an efficient way to simulate thrusters such as ship propellers. The method is widely used in numerical open-water propeller simulations [18]. In a recent article, moving reference frame is used extensively to estimate the self-propulsion parameters for a bulk carrier [19]. However, a major drawback of this method is that it can give different results for different relative positions of the propeller blades.

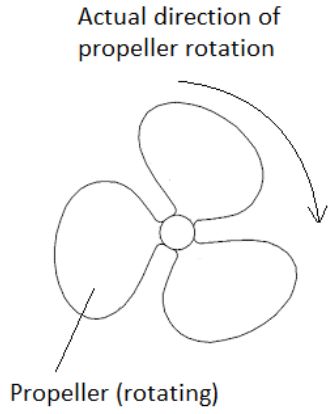

Real propeller rotation

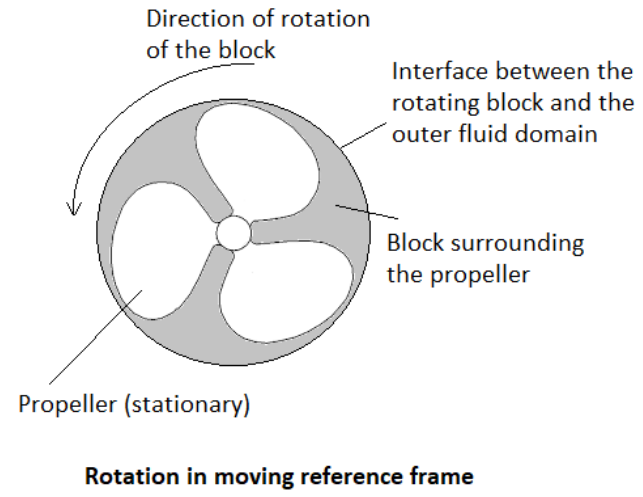

Rotation in moving reference frame

Fig. 5. Working principle of the moving reference frame.

\section{Uncertainty of numerical simulations}

An uncertainty estimation of numerical simulations was made using the appended form of the DARPA Suboff and using the CFD verification and validation methodology of Stern et al. [20]. To get a deeper insight on all the uncertainty parameters presented in this section, please refer to the reference article [20]. The total resistance coefficient was taken as the integral variable. The propeller was not present in the simulations and the speed of the vessel was taken 
as 10knots. The experimental results of resistance are present in Liu and Huang [21]. The numerical simulations were made using the steady state time assumption and the iterative uncertainties were very low compared to the grid uncertainty. Therefore, the total numerical uncertainty was roughly taken in this study as $U_{N} \cong U_{G}$. The total resistance coefficient was obtained using three grid systems and the results are presented in table 1 along with the experimental results.

Table 1. Total resistance coefficients obtained with different grids.

\begin{tabular}{|c|c|c|c|c|}
\hline & Experiment & GRID 1 & GRID 2 & GRID 3 \\
\hline No. of elements & - & $145 \mathrm{k}$ & $411 \mathrm{k}$ & $1062 \mathrm{k}$ \\
\hline$C_{T}$ & $3.297 * 10^{-3}$ & $3.511 * 10^{-3}$ & $3.192 * 10^{-3}$ & $3.050^{*} 10^{-3}$ \\
\hline
\end{tabular}

The estimation of numerical uncertainty was made using grid 2 which has a total number of $411 \mathrm{k}$ grid elements. The grid refinement ratio was taken as $r_{G}=\sqrt{2}$. Following the total resistance coefficient results given in table 1, the parameters of uncertainty for the verification part were calculated as presented in table 2 .

Table 2. Verification parameters for numerical simulations.

\begin{tabular}{|c|c|c|c|c|c|c|c|}
\hline$\varepsilon_{32}$ & $\varepsilon_{21}$ & $R_{G_{2}}$ & $r_{G}$ & $p_{G}$ & $\delta_{R E}$ & $C_{G}$ & $U_{G}$ \\
\hline $1.418 * 10^{-4}$ & $3.192 * 10^{-4}$ & 0.444 & 1.414 & 2.341 & $2.551 * 10^{-4}$ & 1.251 & $3.832 * 10^{-4}$ \\
\hline
\end{tabular}

From table 2, it can be seen that $U_{G}=12 \% S_{G_{2}}$. The parameters for the validation part of the uncertainty study are presented in table 3.

Table 3. Validation parameters for numerical simulations.

\begin{tabular}{|c|c|c|}
\hline Experiment & $S_{G_{2}}$ & Error \\
\hline $3.297^{*} 10^{-3}$ & $3.192 * 10^{-3}$ & $1.046 * 10^{-4}$ \\
\hline
\end{tabular}

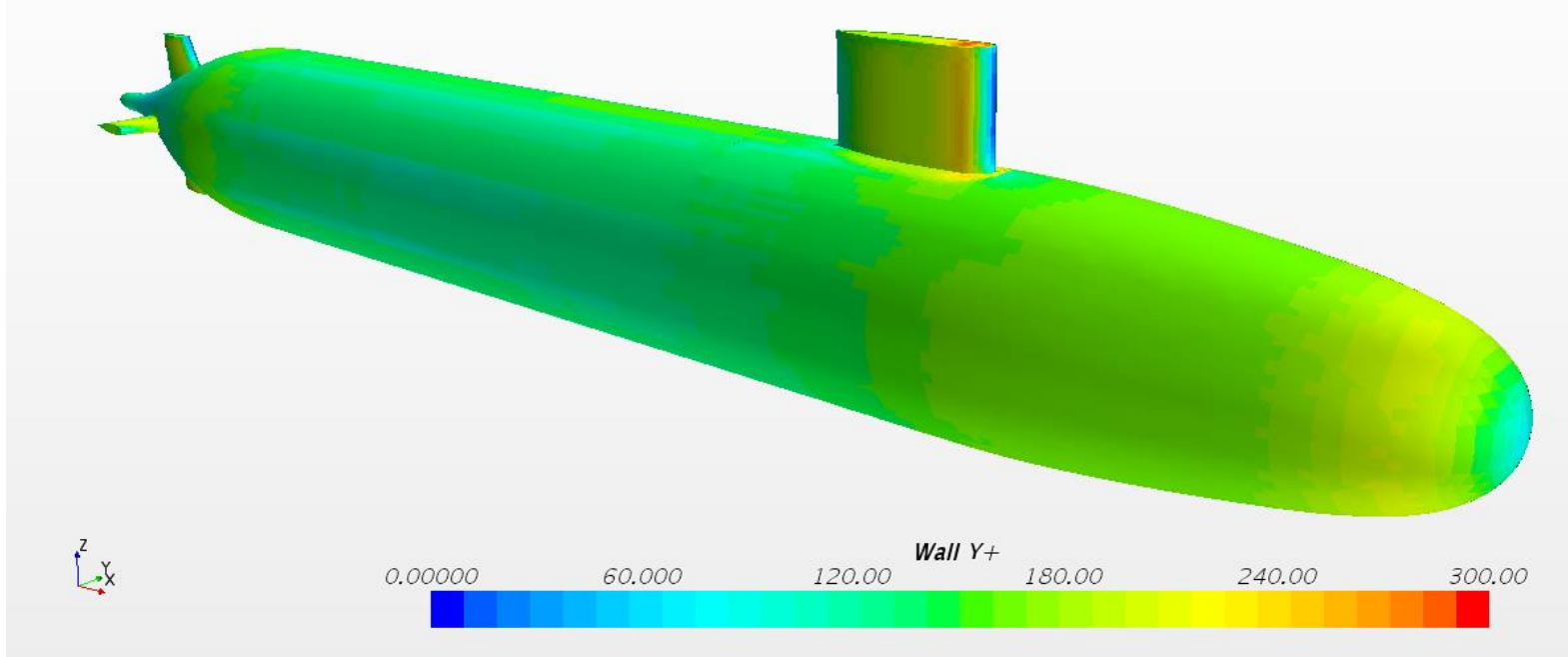

Fig. 6. Wall y+ on DARPA Suboff at 10knots speed. 
The error for grid 2 as compared with the experimental result was found to be $E=$ $3.17 \% D$. The experimental uncertainty was not provided in the reference study; therefore, the validation uncertainty was taken as $U_{V} \cong U_{N}$. The numerical uncertainty was $U_{N}=11.62 \% D$. The error was smaller than the validation uncertainty $E<U_{V}$ and the numerical simulation results were validated. Wall y+ values for grid 2 at a vessel speed of $10 \mathrm{knots}$ is given in figure 6.

\section{DARPA Suboff self-propulsion results}

The self-propulsion points of DARPA Suboff at different velocities were determined using the three different methods explained in this paper. For the self-propelled CFD results, INSEAN E1619 propeller was fitted to the DARPA Suboff similar to [11] and the results were compared where applicable. The geometric properties of the DARPA Suboff and the INSEAN E1619 propeller are given in table 4 and table 5 respectively [11].

Table 4. Geometric properties of the full scale DARPA Suboff.

\begin{tabular}{|l|c|c|}
\hline Hull Length & $\mathrm{m}$ & 4.356 \\
\hline Hull Diameter & $\mathrm{m}$ & 0.508 \\
\hline Propeller Diameter & $\mathrm{m}$ & 0.262 \\
\hline
\end{tabular}

The propeller diameter for the DARPA Suboff was $0.262 \mathrm{~m}$ as stated in table 4 , whereas the original E1619 propeller diameter was $0.485 \mathrm{~m}$. Therefore, a $\lambda=1 / 1.8512$ scaled model of the E1619 propeller was fitted at the stern part of the hull to numerically solve for selfpropulsion directly by CFD. For the case with the virtual disk, a cylinder having a diameter of $0.262 \mathrm{~m}$ was placed at the location of the propeller instead. Calculations were first carried out for no propeller case for two purposes. The first was for the validation of the results with the reference experiments and the second was to gather data (such as the wake fraction $w$ and total towed resistance $R_{T}$ ) for the classical engineering approach (CEA) to estimate the selfpropulsion point of the DARPA Suboff. The vessel was considered to be totally submerged in water; therefore, free water surface effects were not included in the numerical simulations.

Table 5. Geometric properties of the E1619 propeller fitted to DARPA Suboff.

\begin{tabular}{|l|c|c|}
\hline Number of Blades & - & 7 \\
\hline Propeller Diameter & $\mathrm{m}$ & 0.262 \\
\hline Hub Diameter & $\mathrm{m}$ & 0.06 \\
\hline Pitch at r=0.7R & - & 1.15 \\
\hline Chord at r=0.7R & $\mathrm{mm}$ & 3.7 \\
\hline
\end{tabular}

\subsection{No propeller case}

Numerical simulations were carried out to assess the total resistance of the DARPA Suboff and the results were compared with the experiments of Liu and Huang [21]. The comparisons were made for both the bare hull (configuration 1) and fully appended (configuration 8) cases. The results are given in figure 7.

Prediction of total resistance for both configurations of the DARPA Suboff is satisfactory compared to the experiments. There is a small deviation in results for the fully appended case but the results are nearly on top of each other for the bare hull case. The resistance components 
are given in figure 7 (right) for the fully appended case. Pressure resistance is dominant over frictional resistance for all velocities.

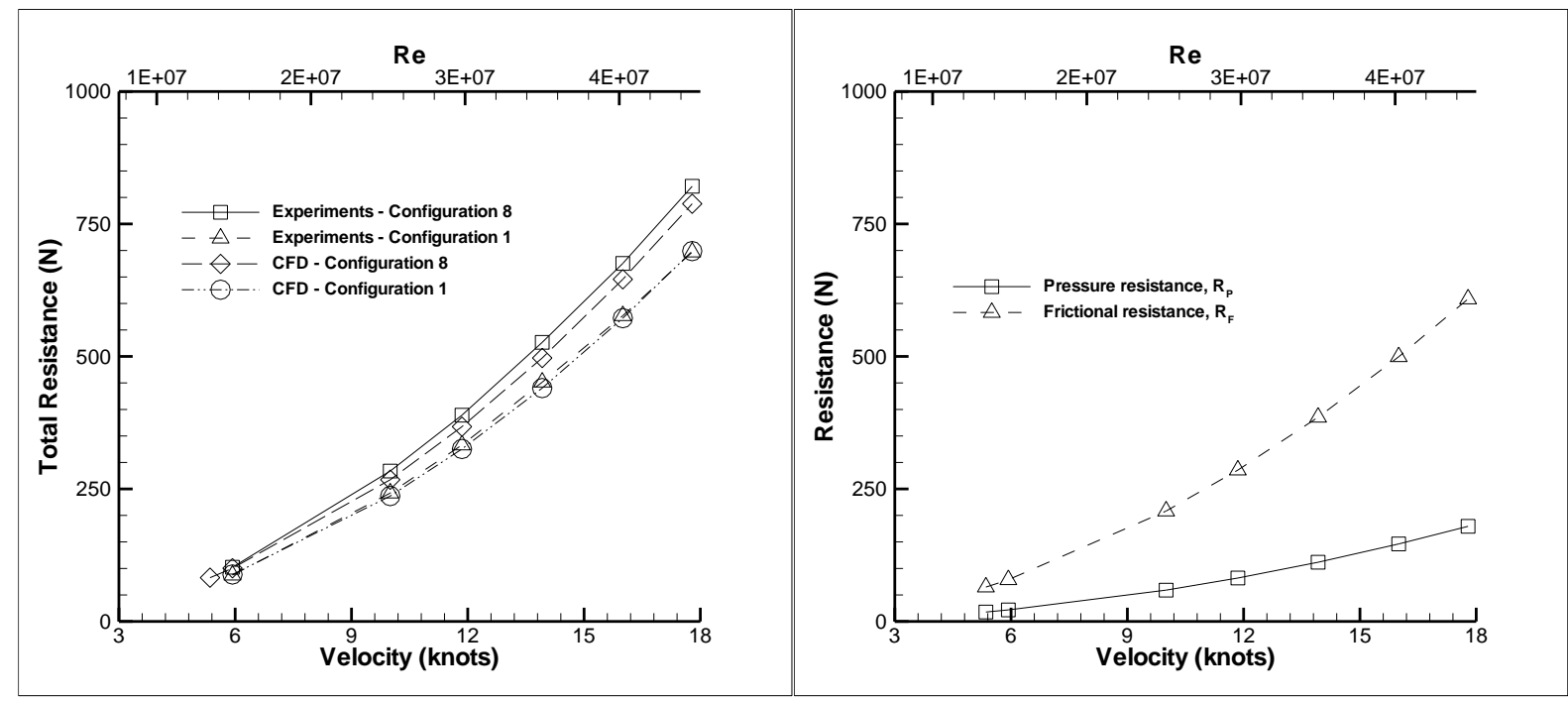

Fig. 7. Total resistance (left) for both configurations and resistance components (right) of DARPA Suboff for configuration 8 at different speeds.

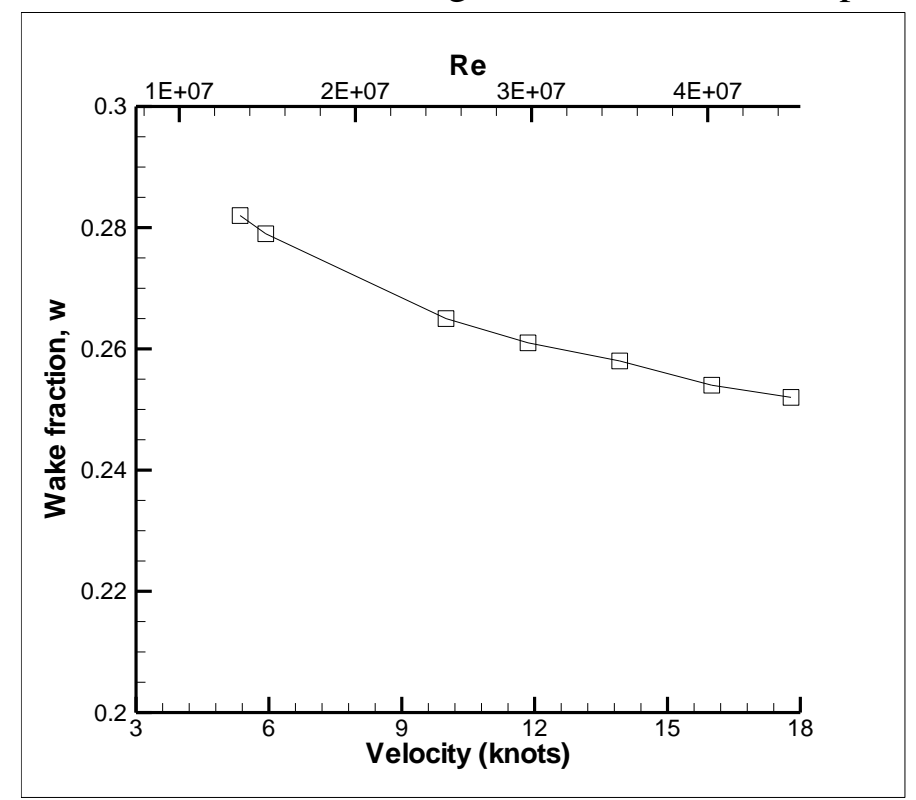

Fig. 8. Wake fraction with respect to changing hull velocity.

Changes in the wake fraction with respect to speed are given in figure 8 . The wake fraction was calculated by equation (1). The wake fraction showed a decreasing trend with respect to increasing hull velocity. Conventional self-propulsion calculations assume wake fraction to be constant but in fact there is a slight decrease in $w$ with increasing ship speed. Changes in $w$ might become important if the ship speed increases (or decreases) dramatically. The contours of the nominal wake for two speeds are given in figure 9. Although it is very hard to distinguish between wake contours in this figure, the wake fraction was remarkably lower at higher speed. 


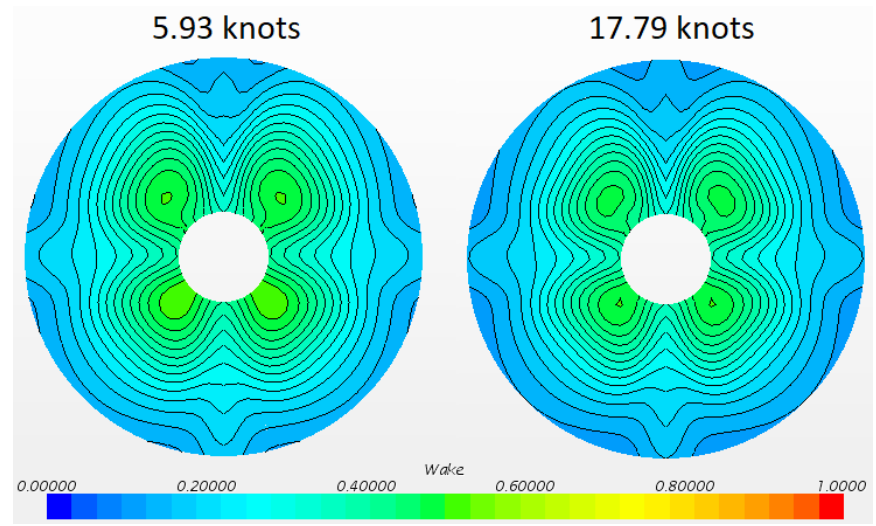

Fig. 9. Nominal propeller wake at different velocities of DARPA Suboff.

\subsection{The case with the propeller}

The case with the propeller was numerically carried out to assess the thrust deduction factor $t$ and the propeller rotation rate $n$. The assessment of the propeller rotation rate $n$ is made in the self-propulsion section. The thrust deduction factor given in figure 10 was calculated by equation (4) using two different methods. The thrust $T$ in equation (4) can numerically be obtained either by using a virtual disk to represent the propeller or modeling the propeller directly. The thrust deduction factor obtained from the virtual disk method was consistently higher than the self-propelled CFD method in all the speeds covered in this study. The underlying physical issue for this miscalculation cannot be foreseen; however, the ship reaches the self-propulsion equilibrium (thrust - resistance equilibrium) later than expected. This is probably based on the actuator disk theory where it is assumed that the disk has zero thickness. In the actual case, propeller blades have a non-negligible thickness which reduce the thrust achieved by the propeller. The self-propelled CFD method showed an increasing trend with increasing velocity whereas the results generated by the virtual disk method were nearly constant.

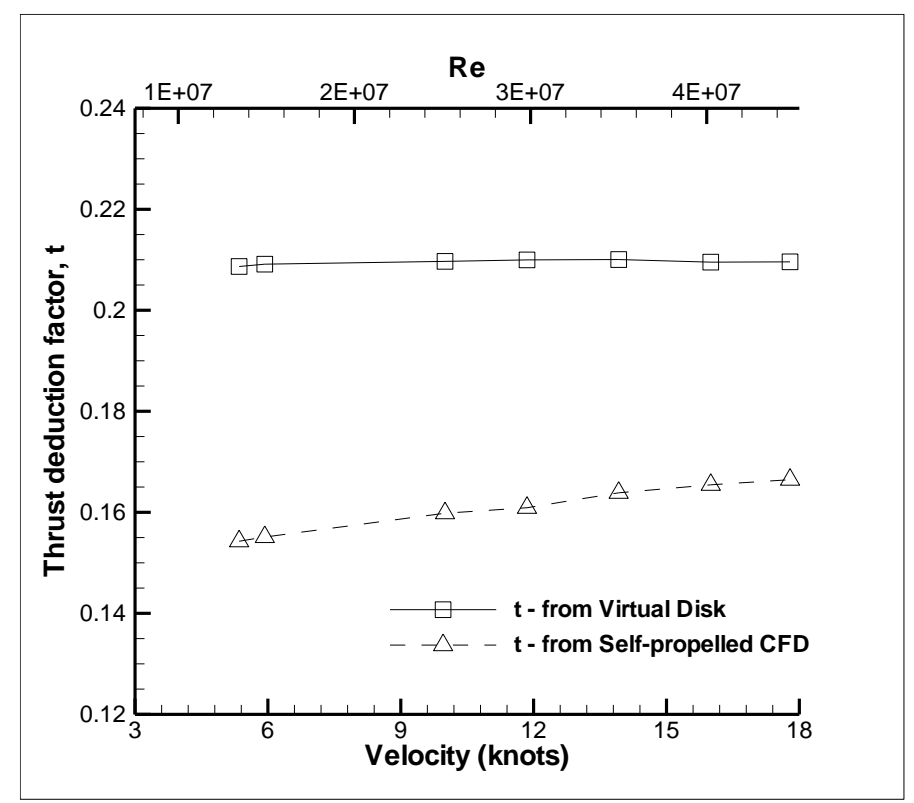

Fig. 10. Thrust deduction factor obtained from different numerical approaches. 


\subsection{Estimation of self-propulsion point}

The estimation of self-propulsion point of the DARPA Suboff was made using three different approaches. The first one was by using the CEA while the second and the third were numerical. The second approach was solving the self-propulsion problem by using a virtual disk to represent the propeller and the third was by direct modeling of the propeller with CFD approach. The obtained results using the three different methods were compared with the results of Chase and Carrica, Ozden and Celik [11, 22] and Sezen, Delen and Bal [23]. They are given in table 6.

In table 6, OWC denotes the open-water curve. All the calculations carried out to estimate the self-propulsion points given in table 6 were made using the experimental OWC. The thrust deduction factor $t$ that was essential to calculate the self-propulsion via the CEA was obtained from the numerical simulations using a virtual disk. Other options were to use the $t$ from selfpropelled CFD or empirical equations. Considering that large deviations in the thrust deduction factor reflect as a minor change in the advance coefficient $J$, carrying out extra calculations were not found to be necessary (a $50 \%$ change in $t$ only reflects as a $3 \%$ change in $J$ ).

Table 6. Self-propulsion assessment of the DARPA Suboff with E1619 propeller at $V=$

\begin{tabular}{|c|c|c|c|c|}
\hline \multicolumn{5}{|l|}{ 5.35knots. } \\
\hline & $J$ & $K_{T}$ & $K_{Q}$ & $\eta_{0}$ \\
\hline Chase and Carrica [11] - Self-propelled CFD & - & 0.2342 & 0.0471 & 0.5927 \\
\hline Chase and Carrica [11] - Using CFD OWC & 0.7498 & 0.2342 & 0.0458 & 0.6115 \\
\hline Chase and Carrica [11] - Using Experimental OWC & 0.7659 & 0.2342 & 0.0435 & 0.6602 \\
\hline Ozden and Celik [22] - Self-propelled CFD & 0.728 & 0.2416 & 0.0464 & 0.6033 \\
\hline Sezen et al. [23] - Self-propelled CFD & - & 0.2363 & 0.4556 & - \\
\hline Present - Self-propelled CFD & 0.7774 & 0.2312 & 0.0461 & 0.6202 \\
\hline Present - CEA & 0.7731 & 0.2336 & 0.0473 & 0.6079 \\
\hline Present - Virtual disk & 0.7271 & 0.2584 & 0.0550 & 0.5437 \\
\hline
\end{tabular}

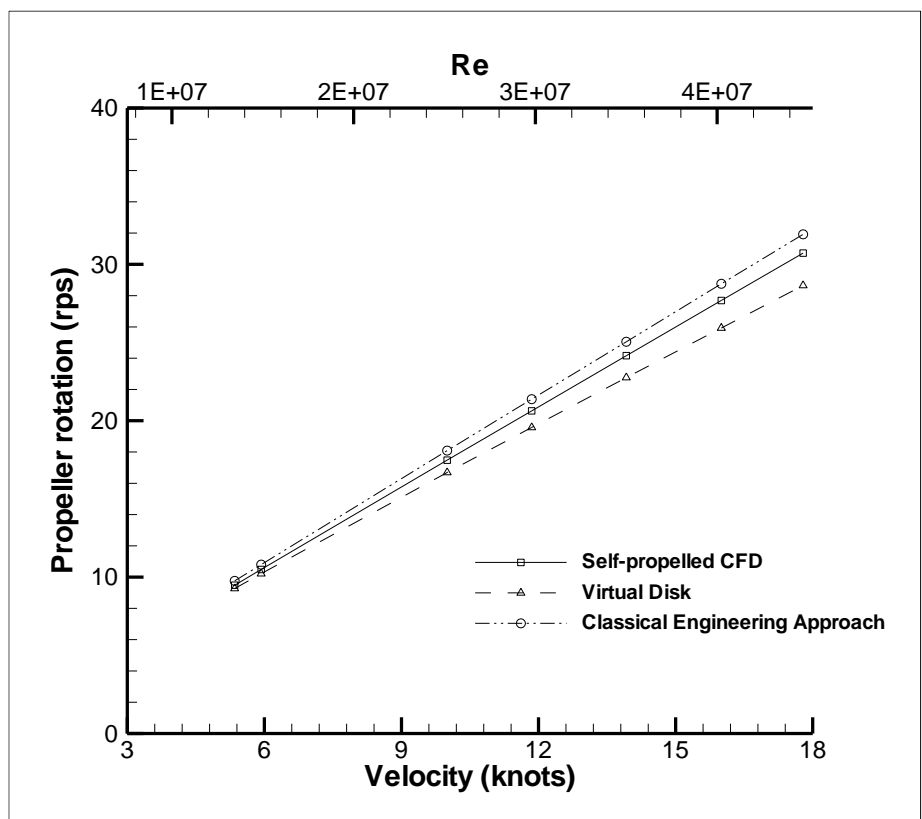

Fig. 11. Propeller rotation rates at self-propulsion point for different speeds of DARPA Suboff. 
All results were found to be in accordance except the virtual disk approximation that predicted lower propeller efficiency $\eta_{0}$ at the self-propulsion point. It was also found out that the results generated by the CEA were promising. CEA predicted similar results with the other time-costly methods and is much more practical than the others.

The propeller rotation rates (rounds per second) obtained by each method are given in figure 11. It was found that all three methods generated close results; although, the discrepancy between results were slightly higher at higher hull velocities.

\section{KRISO Container Ship (KCS) self-propulsion results}

The self-propulsion points of KCS at its service speed $(F r=0.26)$ was calculated using the CEA and direct CFD approach as explained in previous sections. The propeller used was the KP505 propeller and a scaled model of $\lambda=1 / 31.599$ was solved in numerical simulations. The geometric properties of the KCS and the KP505 propeller are given in table 7 and table 8 respectively.

Table 7. Geometric properties of the scaled KCS.

\begin{tabular}{|l|c|c|c|}
\hline Length between perpendiculars & $\mathrm{L}_{\mathrm{pp}}$ & $\mathrm{m}$ & 7.2786 \\
\hline Beam at waterline & $\mathrm{B}$ & $\mathrm{m}$ & 1.019 \\
\hline Draft & $\mathrm{T}_{\mathrm{m}}$ & $\mathrm{m}$ & 0.3418 \\
\hline Wetted surface area w/o rudder & $\mathrm{S}$ & $\mathrm{m}$ & 9.4379 \\
\hline Block coefficient & $\mathrm{C}_{\mathrm{B}}$ & - & 0.6505 \\
\hline Midship section coefficient & $\mathrm{C}_{\mathrm{M}}$ & - & 0.9849 \\
\hline
\end{tabular}

Table 8. Geometric properties of the scaled KP505 propeller.

\begin{tabular}{|l|c|c|}
\hline Number of Blades & - & 5 \\
\hline Propeller Diameter & m & 0.25 \\
\hline Hub Diameter & m & 0.045 \\
\hline
\end{tabular}

\subsection{No propeller case}

Calculations were first carried out to obtain the towed resistance of KCS without the propeller. Then, the self-propelled results were presented using the three mentioned methods. There are many results on the towed resistance values of KCS in the literature. Along with the results obtained in the present study, they are presented in table 9.

Experiments published in Tokyo 2005 CFD Workshop were taken as reference from Carrica et al. and various numerical results are provided in table 9. Carrica et al. have provided a broad list in their study and in this work it was extended to cover some more results from the literature [24]. The second and third rows in the table are the numerical results carried out by Carrica et al. while the fourth (Hamburg Ship Model Basin), fifth (Potsdam Model Basin), sixth (Korean Maritime and Ocean Engineering Research Institute, now named as MOERI) and seventh (Osaka Prefecture University) rows are numerical simulations provided by various institutes or universities from all around the world. All results provided in table 9 were graphed in figure 12 to provide a better insight. 
Table 9. Towed resistance coefficients and nominal wakes for KCS

\begin{tabular}{|l|c|c|c|c|}
\cline { 2 - 5 } \multicolumn{1}{c|}{} & $\mathrm{C}_{\mathrm{T}} * 10^{3}$ & $\mathrm{C}_{\mathrm{P}} * 10^{3}$ & $\mathrm{C}_{\mathrm{F}} * 10^{3}$ & $\mathrm{~W}_{\mathrm{n}}$ \\
\hline Experiments & 3.55 & 0.718 & 2.832 & 0.686 \\
\hline Carrica et al. [24] - DES & 3.575 & 0.737 & 2.838 & 0.723 \\
\hline Carrica et al. [24] - RANS & 3.669 & 0.791 & 2.878 & 0.74 \\
\hline Carrica et al. [24]- HSVA & 3.581 & 0.918 & 2.663 & 0.745 \\
\hline Carrica et al. [24]- SVA & 3.531 & 0.681 & 2.849 & 0.721 \\
\hline Carrica et al. [24]- KRISO & 3.596 & 0.823 & 2.773 & 0.723 \\
\hline Carrica et al. [24] - OPU & 3.545 & 0.86 & 2.685 & 0.634 \\
\hline Kim et al. [25] & 3.537 & 0.736 & 2.801 & - \\
\hline Gao et al. [3] & 3.51 & - & - & - \\
\hline Gaggero et al. [26] & 3.45 & - & - & - \\
\hline Gaggero et al. [6] & 3.504 & 0.642 & 2.862 & 0.721 \\
\hline Shen et al. [27] & 3.52 & 0.699 & 2.821 & 0.742 \\
\hline Starke [28] & 3.585 & 0.638 & 2.947 & - \\
\hline Ozdemir et al. [29] & 3.65 & 0.78 & 2.87 & - \\
\hline Present study & $\mathbf{3 . 6 7 9}$ & $\mathbf{0 . 8 9 6}$ & $\mathbf{2 . 7 8 3}$ & $\mathbf{0 . 7 4 1}$ \\
\hline
\end{tabular}

The total resistance coefficient obtained in the present study was slightly higher than the other results found in the literature. This was due to high pressure resistance predicted in our simulations. Our results were parallel with the numerical results of HSVA. Their results also suggest high pressure resistance which led to higher total resistance. The frictional resistance values of our study seemed close to other results found in the literature with only a $1.7 \%$ difference with experiments. All numerical results predicted high nominal wake values for KCS including our study. They were in between the range $0.72<W_{n}<0.75$ except the numerical results provided by OPU where they have calculated the nominal wake to be $W_{n}=0.634$.

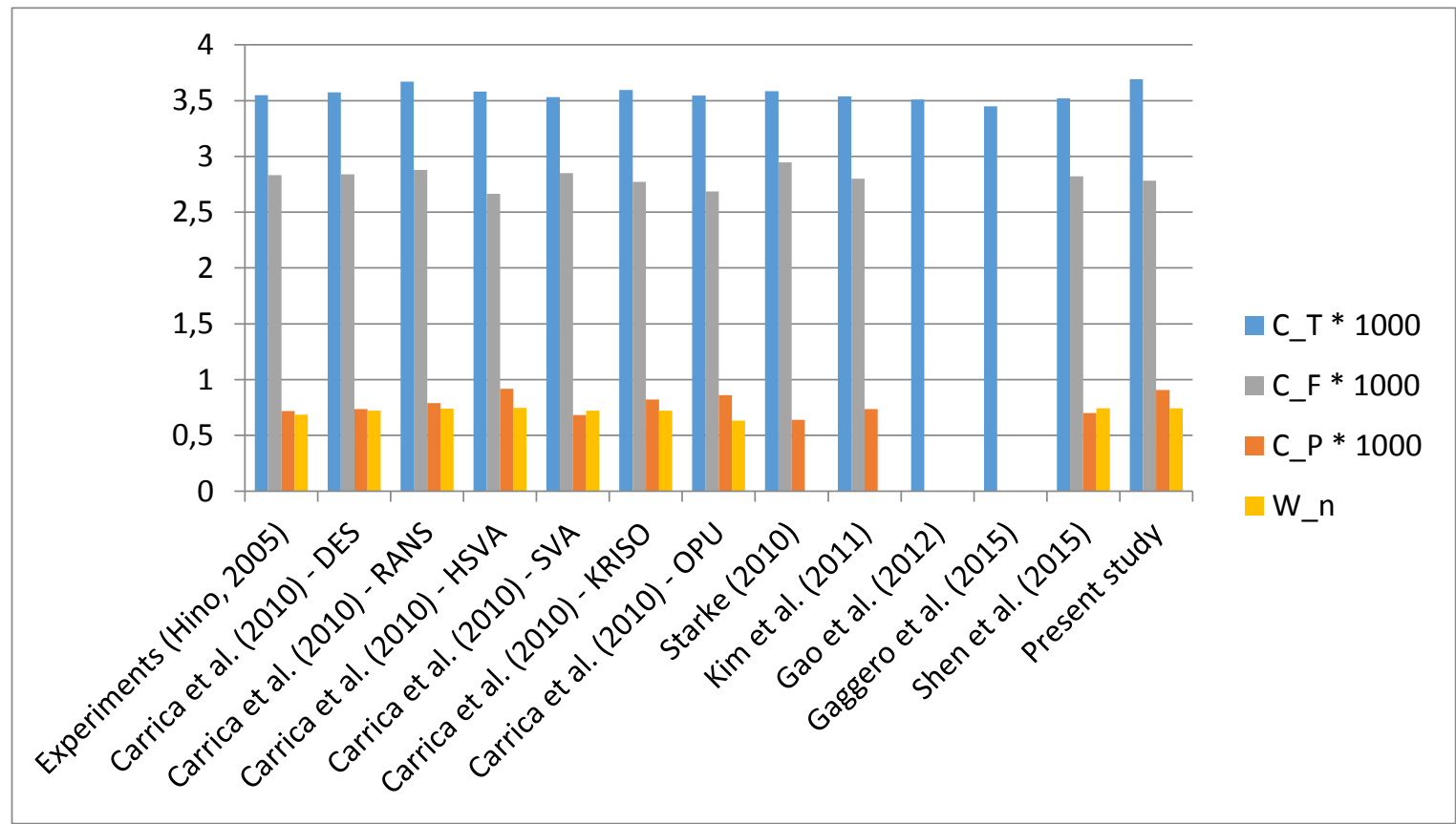

Fig. 12. Graphical comparison of resistance coefficients and nominal wakes in the literature that are provided in table 9. 


\subsection{Estimation of self-propulsion point}

The self-propulsion estimation for KCS was performed using the self-propelled CFD and the CEA methods. Virtual disk results were not presented for surface-piercing ships such as KCS due to very high predictions of thrust deduction factor and the hull efficiency. This was also verified by Dogrul et al. [30]. They have concluded their study by stating that the existence of the free water surface changes the thrust deduction factor dramatically and suggested using other methods for hull-propeller interactions. Due to the absence of virtual disk method in this section, $w$ and $t$ was calculated by the empirical relations suggested by the IMO [15]. The selfpropelled CFD results were compared with the vast amount of data found in the literature. All results are listed in table 10.

Table 10. Resistance coefficients and propulsion estimates for self-propelled KCS.

\begin{tabular}{|c|c|c|c|c|c|c|c|c|c|c|c|c|c|}
\hline \multirow{2}{*}{ (2) -200} & \multirow{2}{*}{$\mathrm{C}_{\mathrm{T}} * 10^{3}$} & \multirow{2}{*}{$\mathrm{C}_{\mathrm{P}} * 10^{3}$} & \multirow{2}{*}{$\mathrm{C}_{\mathrm{F}} * 10^{3}$} & \multirow{2}{*}{$\mathrm{K}_{\mathrm{T}}$} & \multirow[b]{2}{*}{$\mathrm{K}_{\mathrm{Q}}$} & \multirow{2}{*}{\multicolumn{2}{|c|}{\begin{tabular}{|l|l|}
$1-\mathrm{t}$ & $1-\mathrm{W}_{\mathrm{T}}$ \\
\end{tabular}}} & \multirow{2}{*}{$\eta_{0}$} & \multirow{2}{*}{$\eta_{R}$} & \multirow{2}{*}{$\mathrm{J}$} & \multirow{2}{*}{\multicolumn{2}{|c|}{\begin{tabular}{|l|l|}
$\mathrm{n}$ & $\eta_{\mathrm{H}}$ \\
\end{tabular}}} & \multirow[b]{2}{*}{$\eta$} \\
\hline & & & & & & & & & & & & & \\
\hline Experiments & 3.966 & 1.134 & 2.832 & 0.17 & 0.0288 & 0.853 & 0.792 & 0.682 & 1.011 & 0.728 & 9.5 & 1.077 & 0.74 \\
\hline Carrica et al. [24] - DES & 4.011 & 1.172 & 2.847 & 0.1689 & 0.0296 & 0.8725 & 0.803 & 0.683 & 0.976 & 0.733 & 9.62 & 1.0866 & 0.724 \\
\hline $\begin{array}{l}\text { Carrica et al. [24] - } \\
\text { HSVA }\end{array}$ & 3.942 & 1.261 & 2.681 & 0.1702 & 0.03 & 0.865 & 0.789 & 0.667 & 0.981 & 0.725 & 9.56 & 1.0963 & 0.717 \\
\hline Carrica et al. [24] - SVA & 3.878 & 1.024 & 2.854 & 0.163 & 0.0297 & 0.91 & 0.765 & 0.614 & 1.0065 & 0.7075 & 9.5 & 1.1895 & 0.735 \\
\hline $\begin{array}{l}\text { Carrica et al. [24] - } \\
\text { KRISO }\end{array}$ & 3.973 & 1.194 & 2.779 & 0.17 & 0.0228 & 0.857 & - & - & - & - & - & - & - \\
\hline Carrica et al. [24] - OPU & 3.933 & 1.221 & 2.712 & 0.167 & 0.0282 & 0.8515 & 0.7888 & 0.631 & 1.074 & 0.7178 & 9.528 & 1.0795 & 0.7315 \\
\hline Starke [28] & 3.96 & 0.99 & 2.97 & 0.176 & 0.0305 & - & - & - & - & - & 9.328 & - & - \\
\hline Kim et al. [25] & - & - & - & 0.168 & 0.0288 & 0.843 & 0.802 & 0.664 & 1.014 & 0.726 & 9.7 & 1.0511 & 0.708 \\
\hline $\begin{array}{l}\text { Bugalski and Hoffman } \\
\text { [2] }\end{array}$ & 3.804 & - & - & 0.1502 & 0.0283 & - & - & - & - & - & 9.8 & - & - \\
\hline Gao et al. [3] & 3.964 & - & - & 0.165 & 0.029 & 0.852 & 0.772 & - & - & 0.714 & - & 1.1036 & 0.715 \\
\hline Gaggero et al. [26] & 3.754 & - & - & 0.1694 & - & 0.8914 & 0.7471 & - & 1.021 & - & 9.2 & 1.1931 & - \\
\hline Shen et al. [27] & 3.84 & - & - & 0.1682 & 0.029 & 0.8857 & 0.8721 & 0.6785 & 0.9811 & 0.7363 & 9.3231 & 1.0156 & 0.7429 \\
\hline Gaggero et al. [6] & - & - & - & - & - & 0.856 & 0.769 & - & - & - & 9.6 & 1.1131 & - \\
\hline Gaggero et al. [31] & - & - & - & - & - & 0.8688 & 0.7618 & - & - & - & 9.656 & 1.1405 & - \\
\hline $\begin{array}{l}\text { Present study - Self } \\
\text { Propelled CFD }\end{array}$ & 3.983 & 1.284 & 2.699 & 0.167 & 0.028 & 0.891 & 0.7945 & 0.6818 & 1.0347 & 0.721 & 9.68 & 1.122 & 0.7915 \\
\hline Present study - CEA & - & - & - & 0.1952 & 0.032 & 0.8165 & 0.7378 & 0.637 & - & 0.6613 & 9.80 & 1.1066 & - \\
\hline
\end{tabular}

Table 10 covers a broad range of latest results for the self-propelled case of KCS at 1/31.599 model scale. Experimental results taken from Carrica et al. were again taken as reference for the numerical studies [24]. The frictional resistance coefficient of the experiment was calculated by the ITTC 1957 friction line given as $C_{F}=0.075 /(\log R e-2)^{2}$. The pressure resistance coefficient was not measured but calculated by $C_{P}=C_{T}-C_{F}$. The table also covers two results carried out in the present study. The self-propelled CFD results were 
produced with respect to the 1978 ITTC performance prediction method and the practical guidelines for ship self-propulsion CFD $[16,32]$. For the CEA; $R_{T}$ was taken from numerical simulations of KCS without the propeller and $K_{T}$ was taken from experimental open-water propeller performance results. The other two inputs, $w$ and $t$, were taken from empirical relations recommended by IMO [15]. IMO recommends wake fractions for block coefficients of $0.5,0.6,0.7$ and $0.8+$, not providing any data for intermediate values. Therefore, a third order polynomial was fitted to the recommended values of wake fraction for one propeller ships and using the equation of this polynomial, $w$ for KCS was calculated using block coefficient value from table $7, C_{B}=0.6505$. IMO recommends using $t=0.7 \mathrm{w}$ [15], therefore, thrust deduction factor $t$ of KCS was calculated using this equation.

A close observation of table 10 indicates that the self-propelled CFD results generated in this study are in accordance with the experiments and the other numerical results that may be found in the literature. On the other hand, the propulsive estimates generated by the CEA were found to be fair predictions. The results of CEA were not as good as the numerical studies implementing the finite volume method. However; considering the amount of time spent, CEA was found to be very practical and a good method to refer to at the initial design stages of a ship. The results presented in table 10 are visualized in figure 13.

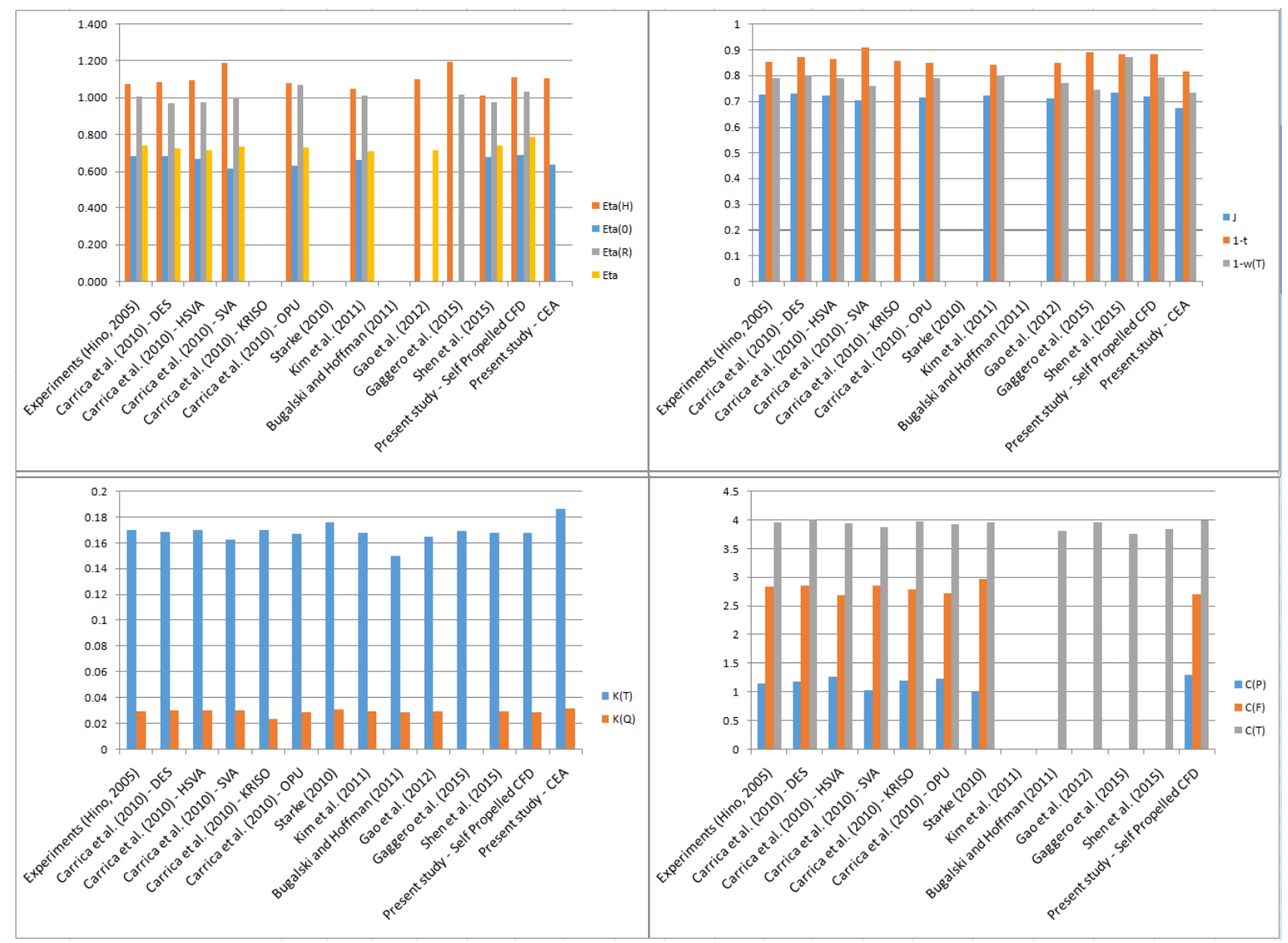

Fig. 13. A summary of resistance coefficients and propulsion factors that are provided in table 10. 
Table 11. Propulsion factor estimates using different inputs for the CEA.

\begin{tabular}{|l|c|c|c|c|c|c|c|}
\cline { 2 - 8 } \multicolumn{1}{c|}{} & $\mathrm{K}_{\mathrm{T}}$ & $\mathrm{K}_{\mathrm{Q}}$ & $1-\mathrm{t}$ & $1-\mathrm{W}_{\mathrm{T}}$ & $\eta_{0}$ & $\mathrm{~J}$ & $\mathrm{n}$ \\
\hline Experiments & 0.17 & 0.0288 & 0.853 & 0.792 & 0.682 & 0.728 & 9.5 \\
\hline CEA with CFD + IMO & 0.1867 & 0.0312 & 0.8165 & 0.7378 & 0.6464 & 0.6779 & 9.56 \\
\hline CEA with experiments & 0.1701 & 0.0291 & $0.853 *$ & $0.792 *$ & 0.6621 & 0.7106 & 9.79 \\
\hline
\end{tabular}

* Values taken from the experimental results published in (Carrica et al., 2010) [24].

The predictions of the CEA were better for the DARPA Suboff which was presented in the previous section. This is due to using empirical relations provided by the IMO which were not very accurate. IMO's recommendation generates $1-W_{T}=0.7378$ and $1-t=0.8165$ and these inputs are not very good estimates compared to the experimental values of $1-W_{T}=$ 0.792 and $1-t=0.853$. Using the experimental values for the inputs $w, t$ and $R_{T}$, the estimation of the propulsion factors with the CEA become significantly enhanced as given in table 11 [15]. If CEA is supported by right interaction parameter values ( $w$ and $t$ ) the results become very close to experimental results. The slight difference compared to experiments arise due to the difference in total resistance and the errors made during the interpolation in the thrust identity method.

\section{Duisburg Test Case (DTC) self-propulsion results}

The self-propulsion point of DTC at a Froude number of $F r=0.218$ was calculated in this section. A scaled model of $\lambda=1 / 59.407$ was used in the calculations in accordance with the experimental results published in the reference study [33]. The geometric properties of DTC and its propeller are given in table 12 and table 13 respectively.

Table 12. Geometric properties of the scaled DTC.

\begin{tabular}{|l|l|l|l|}
\hline Length between perpendiculars & $\mathrm{L}_{\mathrm{pp}}$ & $\mathrm{m}$ & 5.976 \\
\hline Beam at waterline & $\mathrm{B}$ & $\mathrm{m}$ & 0.859 \\
\hline Draft & $\mathrm{T}_{\mathrm{m}}$ & $\mathrm{m}$ & 0.244 \\
\hline Wetted surface area & $\mathrm{S}$ & $\mathrm{m}^{2}$ & 6.243 \\
\hline Block coefficient & $\mathrm{C}_{\mathrm{B}}$ & - & 0.661 \\
\hline Displacement & $\nabla$ & $\mathrm{m}^{3}$ & 0.827 \\
\hline Speed & $\mathrm{V}$ & $\mathrm{m} / \mathrm{s}$ & 1.668 \\
\hline
\end{tabular}

Table 13. Geometric properties of the scaled propeller.

\begin{tabular}{|l|l|l|}
\hline Number of blades & - & 5 \\
\hline Propeller diameter & $\mathrm{m}$ & 0.15 \\
\hline Hub diameter & $\mathrm{m}$ & 0.0264 \\
\hline
\end{tabular}

\subsection{No propeller case}

Experimental results can be found in the reference study for the resistance characteristics of the vessel without the propeller [33]. The CFD results for the no propeller case in comparison with the experiments are given in figure 14. 


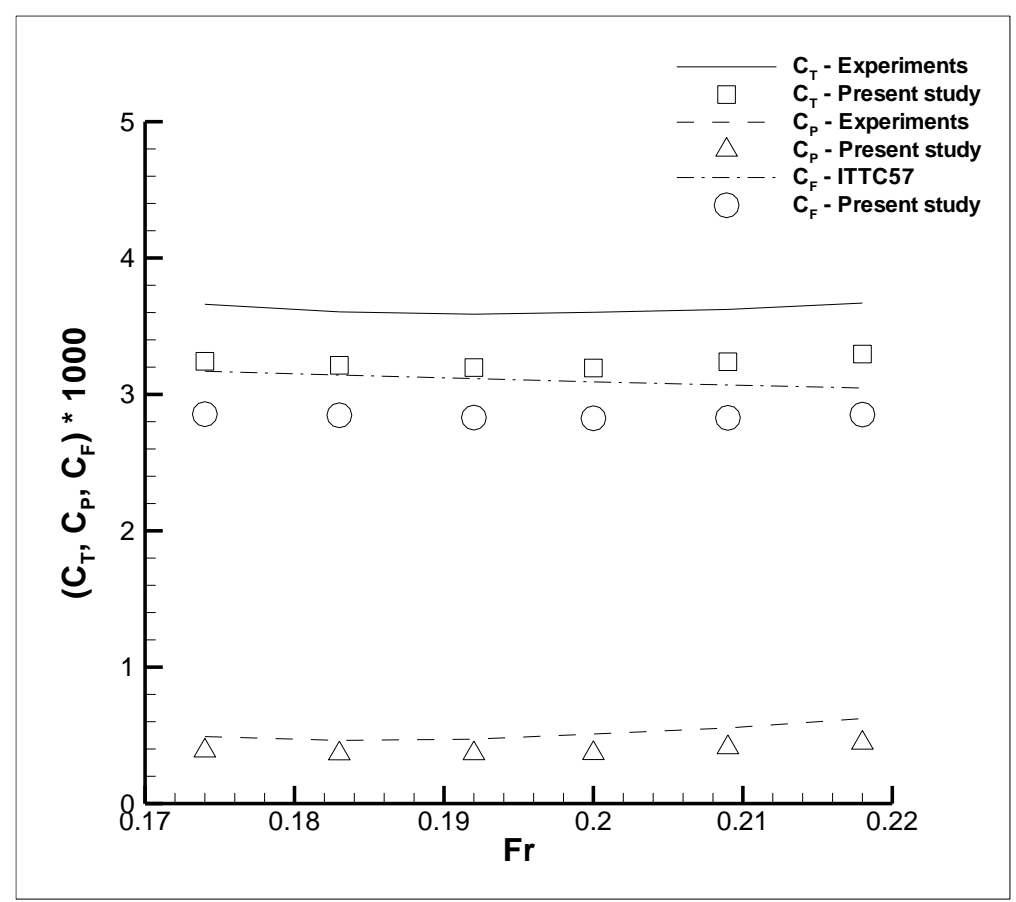

Fig. 14. Numerical results for the no propeller case of DTC in comparison with the experiments.

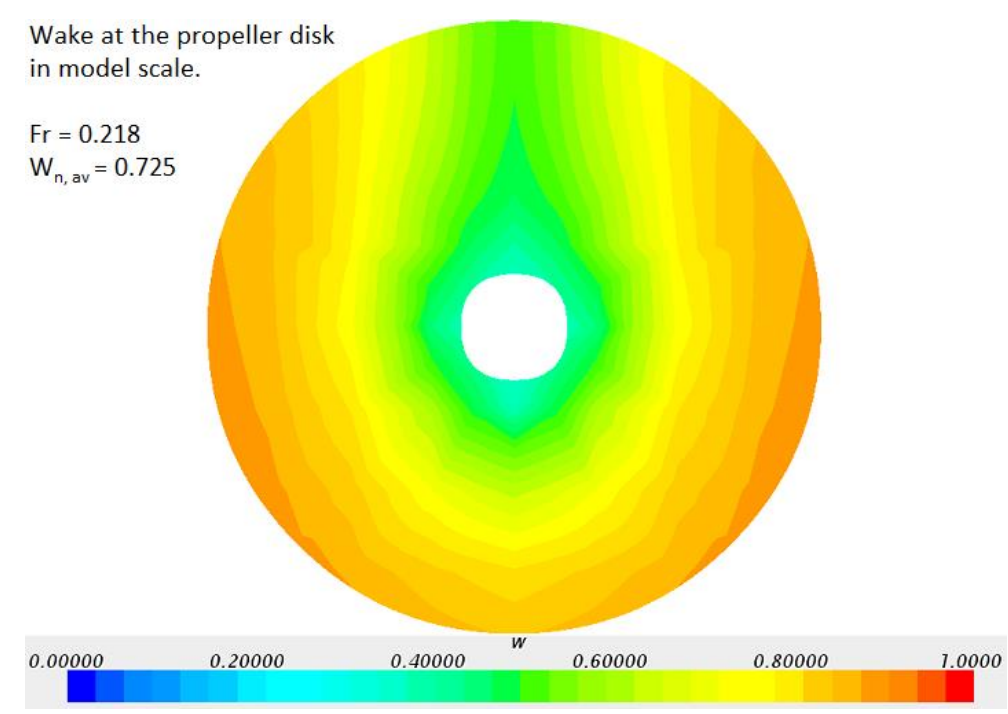

Fig. 15. Wake at the propeller disk.

Although the CFD generated results in this study were lower, it can be said that the results were still in accordance with the experiments. It was found that the general trend of the two $C_{T}$ curves agreed well and the difference in the total resistance originated from the frictional resistance. This was possibly due to the vessel being forced to be held stationary in our numerical simulations while it was free to sink and trim in the experiments. Still, numerical simulations in this study suggested closer results to the experiments when compared with the results published by Kinaci and Gokce [34]. There are some other numerical studies mentioning the no propeller case of DTC and approaching the resistance problem by some other methods. The readers are referred to [35] to compare RANSE + VOF based numerical results of this study with only RANSE based results (double body approach) and [36] with RANSE + empirical approach based results. 
The wake at the propeller disk at $F r=0.218$ is given in figure 15 . Digital values of resistance and wake are summarized in table 14. These values were used in CEA to estimate the self-propulsion point of DTC at $F r=0.218$.

Table 14. Numerical results for no propeller case at $F r=0.218$.

\begin{tabular}{|c|c|c|c|}
\hline \multicolumn{4}{|c|}{ DTC - Model Scale: $1 / 59.407$} \\
\hline $\mathrm{C}_{\mathrm{T}} * 10^{3}$ & $\mathrm{C}_{\mathrm{P}} * 10^{3}$ & $\mathrm{C}_{\mathrm{F}} * 10^{3}$ & $\mathrm{~W}_{\mathrm{n}}$ \\
\hline 3.296 & 0.444 & 2.852 & 0.725 \\
\hline
\end{tabular}

\subsection{Estimation of self-propulsion point}

Estimation of self-propulsion point of DTC was made at $F r=0.218$ using the CEA and the self-propelled CFD. The four parameters as inputs to the CEA were derived from:

- $\quad K_{T}$ : value obtained from the open-water propeller results found in the reference study [33].

- $\quad R_{T}$ : calculated using table 12 and table 14 .

- $\quad w$ : value calculated from the table provided by IMO [15].

- $\quad t$ : calculated by using the equation $t=0.7 * w$ provided by IMO [15].

Using these four inputs and calculating the self-propulsion estimates, table 15 was obtained for DTC. A close observation of this table points to the fact that the propulsion estimates calculated with both methods were in accordance with each other.

Table 15. Propulsion estimates for self-propelled DTC.

\begin{tabular}{|l|c|c|c|c|c|c|c|c|c|c|c|c|c|}
\cline { 2 - 13 } \multicolumn{1}{c|}{} & $\mathrm{C}_{\mathrm{T}} * 10^{3}$ & $\mathrm{C}_{\mathrm{P}} * 10^{3}$ & $\mathrm{C}_{\mathrm{F}} * 10^{3}$ & $\mathrm{~K}_{\mathrm{T}}$ & $\mathrm{K}_{\mathrm{Q}}$ & $1-\mathrm{t}$ & $1-\mathrm{W}_{\mathrm{T}}$ & $\eta_{\mathrm{O}}$ & $\eta_{\mathrm{R}}$ & $\mathrm{J}$ & $\mathrm{n}$ & $\eta_{\mathrm{H}}$ & $\eta$ \\
\hline $\begin{array}{l}\text { el Moctar et al. [33] } \\
\begin{array}{l}\text { Present study } \\
\text { Self propelled CFD }\end{array}\end{array}$ & - & - & - & - & - & 0.91 & 0.725 & 0.592 & 0.993 & - & - & 1.255 & - \\
\hline $\begin{array}{l}\text { Present study } \\
\text { CEA }\end{array}$ & - & - & - & 0.205 & 0.033 & 0.812 & 0.732 & 0.633 & - & 0.639 & 12.74 & 1.110 & - \\
\hline
\end{tabular}

There are some experimental data in el Moctar et al. which are also presented in table 15 and our results generated by two different methods in comparison with experiments were found to be satisfactory [33]. The biggest discrepancy was in thrust deduction factor $t$ which was also reflected on the hull efficiency $\eta_{H}$. DTC is a relatively new benchmark ship and due to this reason, studies focusing on this ship are limited in the literature. There is a recent study on DTC which also covers self-propulsion estimation by Sigmund and el Moctar but it was made for a different ship scale $(\lambda=1 / 63.65)$ and a lower Froude number $(F r=0.087)$ [37].

\section{Conclusions}

In this study, estimation of self-propulsion point was presented for three ships in comparison with other results found in the literature. The self-propelled CFD approach implemented in this study was found to be in accordance with the experiments and other numerical studies. Using a virtual disk to represent the propeller is also a method to estimate the self-propulsion point and generated close results for the DARPA Suboff when compared with the results of other researchers in the field. However, virtual disk numerical model can be applied on self-propulsion simulations which only requires the open-water propeller 
performance as an input. Results generated by the virtual disk approach were not satisfactory in numerical simulations where free water surface was present. Although satisfactory accordance was found for the DARPA Suboff, the results of self-propulsion for KCS and DTC were not compatible.

It was one of the main goals of this study to show the robustness of the classical engineering approach on predicting the self-propulsion points of marine vehicles. Using some empirical relations and open-water propeller results, the basic approach returns quite compatible results with experiments and numerical simulations. Considering the practicality of this engineering approach, it is believed that it can be used at least during the pre-design stages of a ship.

It is believed that it would be interesting to challenge the classical engineering approach with planing hulls or hulls with multiple propellers. In this respect, future studies are expected to be made for different types of ships such as planing hulls, catamarans and twin-propeller ships.

\section{Acknowledgements}

The authors are grateful to Dr. Francesco Salvatore and Dr. Pablo Carrica and acknowledge the support of CNR-INSEAN for providing the E1619 propeller geometry. The authors declare that they have no conflict of interest and there is no funding source. The article does not contain any studies with human participants or animals performed by any of the authors.

\section{REFERENCES}

[1] A. Pecoraro, F.D. Felice, M. Felli, F. Salvatore, M. Viviani, An improved wake description by higher order velocity statistical moments for single screw vessel, Ocean Engineering. 108(2015) 181-190. https://doi.org/10.1016/j.oceaneng.2015.07.038

[2] T. Bugalski, P. Hoffman, Numerical simulation of the self-propulsion model tests, Second International Symposium on Marine Propulsors - SMP'11, Hamburg, Germany,(2011).

[3] Q. Gao, W. Jin, D. Vassalos, The calculations of propeller induced velocity by RANS and momentum theory, Journal of Marine Science and Application, 11(2012) 164-168. https://doi.org/10.1007/s11804012-1118-1

[4] F. Stern, H.T. Kim, V.C. Patel, H.C. Chen, A viscous-flow approach to the computation of propeller-hull interaction, Journal of Ship Research, 32(4)(1988) 246-262.

[5] S. Berger, M. Druckenbrod, M. Greve, M. Abdel-Maksoud, L. Greitsch, An efficient method for the investigation of propeller hull interaction, $14^{\text {th }}$ Numerical Towing Tank Symposium - NUTTS 2011, Pool, United Kingdom, (2011).

[6] S. Gaggero, D. Villa, M. Viviani, An extensive analysis of numerical ship self-propulsion prediction via coupled BEM/RANS approach, Applied Ocean Research, 66(2017) 55-78. https://doi.org/10.1016/j.apor.2017.05.005

[7] D. Villa, S. Gaggero, S. Brizzolara, Ship self propulsion with different CFD methods: from actuator disk to viscous inviscid unsteady coupled solvers, $10^{\text {th }}$ International Conference on Hydrodynamics, St. Petersburg, Russia (2012).

[8] B. Starke, J. Bosschers, Analysis of scale effects in ship powering performance using a hybrid RANSBEM approach, 29 ${ }^{\text {th }}$ Symposium on Naval Hydrodynamics, Gothenburg, Sweden (2012).

[9] M.A. Castro, P.M. Carrica, F. Stern, Full scale self-propulsion computations using discretized propeller for the KRISO container ship KCS, Computers \& Fluids, 51(2011) 35-47. https://doi.org/10.1016/j.compfluid.2011.07.005

[10] L. Da-Qing, Validation of RANS predictions of open water performance of a highly skewed propeller with experiments, Journal of Hydrodynamics, Ser. B, 18(2006) 520-528. 
[11] N. Chase, P.M. Carrica, Submarine propeller computations and application to self-propulsion of DARPA Suboff, Ocean Engineering, 60(2013) 68-80. https://doi.org/10.1016/j.oceaneng.2012.12.029

[12] W. Chao, S. Sheng-xia, C. Xin, Y. Li-yu, Numerical simulation of hydrodynamic performance of ice class propeller in blocked flow-using overlapping grids method, Ocean Engineering, 141(2017) 418-426. https://doi.org/10.1016/j.oceaneng.2017.07.028

[13] L. Z. Wang, C.Y. Guo, Y.M. Su, T.C. Wu, A numerical study on the correlation between the evolution of propeller trailing vortex wake and skew of propellers, International Journal of Naval Architecture and Ocean Engineering, 10(2)(2018) 212-224. https://doi.org/10.1016/j.ijnaoe.2017.07.001

[14] J.S. Go, H.S. Yoon,J.H. Jung, Effects of a duct before a propeller on propulsion performance, Ocean Engineering, 136 (2017) 54-66. https://doi.org/10.1016/j.oceaneng.2017.03.012

[15] IMO Resolution MEPC.232(65), 2013 Interim guidelines for determining minimum propulsion, Power to maintain the manoeuverability of ships in adverse conditions, Annex 16.

[16] ITTC 7.5-02-03-01.4:2011, Recommended procedures and guidelines, 1978 ITTC performance prediction method, revision 03.

[17] E. Begovic, C. Bertorello, S. Mancini, Hydrodynamic performances of small size SWATH craft, Brodogradnja, 66(4)(2015) 1-22.

[18] S.E. Belhenniche, A. Mohammed, O. Imine, F. Celik, Effect of geometric configurations on hydrodynamic performance assessment of a marine propeller, Brodogradnja, 67(4)(2017) 31-48. https://doi.org/10.21278/brod67403

[19] A. Farkas, N. Degiuli, I. Martic, Assessment of hydrodynamic characteristics of a full-scale ship at different draughts, Ocean $\quad$ Engineering, 135-152. https://doi.org/10.1016/j.oceaneng.2018.03.002

[20] F. Stern, R.V. Wilson, H.W. Coleman, E.G. Paterson, Comprehensive approach to verification and validation of CFD simulations - Part 1: Methodology and procedures, Journal of Fluids Engineering Transactions of the ASME, 123(4)(2001) 793-802.

[21] H.L. Liu, T.T. Huang, Summary of DARPA Suboff experimental program data, NSWCCD, Report no.: CRDKNSWC/HD-1298-11v (1998).

[22] Y.A. Ozden, F. Celik, Numerical investigation of the effects of underwater aft cone angle and length-tobeam ratio on hull efficiency, GMO Journal of Ship and Marine Technology, 208(2017) 72-88.

[23] S. Sezen, C. Delen, S. Bal, Investigation of self-propulsion of DARPA Suboff by RANS method, Ocean Engineering, 150(2018) 258-271. https://doi.org/10.1016/j.oceaneng.2017.12.051

[24] P.M. Carrica, A.M. Castro, F. Stern, Self-propulsion computations using a speed controller and a discretized propeller with dynamic overset grids, Journal of Marine Science and Technology, 15(2010) 316-330. https://doi.org/10.1007/s00773-010-0098-6

[25] J. Kim, R. Park, K.S. Kim, S.H. Van, Y.C. Kim, Development of a numerical method for the evaluation of ship resistance and self-propulsion performances, Journal of the Society of Naval Architects of Korea, 48(2)(2011) 147-157 (In Korean). https://doi.org/10.3744/SNAK.2011.48.2.147

[26] S. Gaggero, D. Villa, M. Viviani, The KRISO Container Ship (KCS) test case: an open source overview, VI International Conference on Computational Methods in Marine Engineering - MARINE 2015, Rome, Italy (2015).

[27] Z. Shen, D. Wan, P.M. Carrica, Dynamic overset grids in OpenFOAM with application to KCS selfpropulsion and maneuvering, Ocean Engineering, 108(2015) 287-306. https://doi.org/10.1016/j.oceaneng.2015.07.035

[28] B. Starke, Viscous free-surface power prediction for self-propulsion using a hybrid RANS-BEM coupling procedure (PARNASSOS-PROCAL), 2015 CFD Workshop, Tokyo, Japan (2015).

[29] Y.H. Ozdemir, T. Cosgun, A. Dogrul, B. Barlas, A numerical application to predict the resistance and wave pattern of KRISO Container Ship, Brodogradnja, 67(2)(2016) 47-65. https://doi.org/10.21278/brod67204

[30] A. Dogrul, Y. H. Ozdemir, S. Sezen, B. Barlas, Uncertainty Assessment and Self-Propulsion Estimation of Duisburg Test Case, $3^{\text {rd }}$ International Symposium on Naval Architecture and Maritime, Istanbul, Turkey (2018).

[31] S. Gaggero, T. Gaggero, G. Tani, G. Vernengo, M. Viviani, D. Villa, Ship self-propulsion performance prediction by using OpenFOAM and different simplified propeller models, Progress in Maritime Technology and Engineering, Lisbon, Portugal (2018). 
[32] ITTC 7.5-03-03-01:2014, Recommended procedures and guidelines, Practical guidelines for ship selfpropulsion CFD.

[33] O. el Moctar, V. Shigunov, T. Zorn, Duisburg Test Case: Post-Panamax Container Ship for Benchmarking, Ship Technology Research, 59(3)(2012) 50-65. https://doi.org/10.1179/str.2012.59.3.004

[34] O.K. Kinaci, M.K. Gokce, A computational hydrodynamic analysis of Duisburg Test Case with free surface and propeller, Brodogradnja, 66(4)(2015) 23-38.

[35] O.K. Kinaci, A. Kukner, S. Bal, On propeller performance of DTC Post-Panamax Container Ship, International Journal of Ocean System Engineering, 3(2)(2013) 77-89. https://doi.org/10.5574/IJOSE.2012.3.2.077

[36] H. Sukas, M. Kantaroglu, O.K. Kinaci, An adjoint numerical/empirical approach to predict the total resistance of ships, GMO Journal of Ship and Marine Technology, 208(2017) 31-44.

[37] S. Sigmund, O. el Moctar, Numerical and experimental investigation of propulsion in waves, Ocean Engineering, 144(2017) 35-49. https://doi.org/10.1016/j.oceaneng.2017.08.016

Submitted: $\quad$ 21.02.2018. $\quad$ Omer Kemal Kinaci kinacio@itu.edu.tr

Istanbul Technical University

Accepted: $\quad$ 19.10.2018. Metin Kemal Gokce

Yildiz Technical University

Cukurova University

Ahmet Dursun Alkan

Yildiz Technical University

Abdi Kukner

Istanbul Technical University 